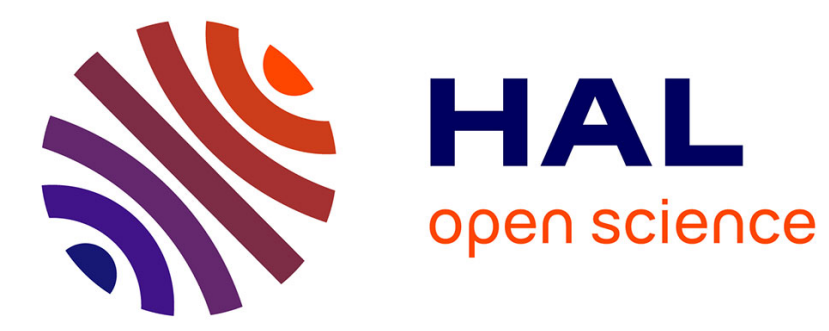

\title{
Chemo-Mechanical Effects in Mortar Beams Subjected to Water Hydrolysis
}

\author{
Caroline Le Bellégo, Bruno Gérard, Gilles Pijaudier-Cabot
}

\section{To cite this version:}

Caroline Le Bellégo, Bruno Gérard, Gilles Pijaudier-Cabot. Chemo-Mechanical Effects in Mortar Beams Subjected to Water Hydrolysis. Journal of Engineering Mechanics - ASCE, 2000, 126 (3), pp.266-272. 10.1061/(ASCE)0733-9399(2000)126:3(266) . hal-01005860

\section{HAL Id: hal-01005860 https://hal.science/hal-01005860}

Submitted on 3 Jul 2017

HAL is a multi-disciplinary open access archive for the deposit and dissemination of scientific research documents, whether they are published or not. The documents may come from teaching and research institutions in France or abroad, or from public or private research centers.
L'archive ouverte pluridisciplinaire HAL, est destinée au dépôt et à la diffusion de documents scientifiques de niveau recherche, publiés ou non, émanant des établissements d'enseignement et de recherche français ou étrangers, des laboratoires publics ou privés. 


\title{
Chemo-Mechanical Effects in Mortar Beams SubJected to Water Hydrolysis
}

\author{
By C. Le Bellégo, ${ }^{1}$ B. Gérard, ${ }^{2}$ and G. Pijaudier-Cabot ${ }^{3}$
}

\begin{abstract}
Reliable predictions of the long-term behavior of concrete structures require both an accurate knowledge of the various degradation mechanisms that affect the structures over their lifetime and the use of simulation tools. Leaching due to aggressive water can be responsible for a loss of mechanical properties and stability of concrete structures. This paper focuses on coupled chemo-mechanical effects on concrete structures subjected to aggressive water inducing calcium leaching. Experimental investigations on mortar bending beams and their analysis are detailed. The response of leached mortar beams is deduced from these tests. It is found that the stiffness of mortar decreases, along with its strength, as the chemical attack progresses. The size effect on geometrically similar bending beams at various stages of degradation is studied experimentally. Due to leaching, the brittleness of the structures is increased and the fracture energy decreases.
\end{abstract}

\section{INTRODUCTION}

Reliable predictions of the very long-term behavior of concrete structures (i.e., over a few hundred years) require both a good knowledge of the various degradation mechanisms that affect structures over their lifetime and the extensive use of simulation tools. One of the main mechanisms of degradation is leaching due to aggressive water and, particularly, calcium leaching, as calcium is the most important element in the hydrated cement paste.

The main consequences on the cement paste microstructure are an increase of porosity and, at the macrolevel, a decrease of the mechanical properties of the material with increasing time. As leaching is a very slow process, experimental studies need the implementation of accelerated procedures; ammonium nitrate has been chosen by a few authors as a representative aggressive solution for such accelerated experiments. For example, Goncalves and Rodrigues (1991) have studied, for 14 years, the influence of calcium leaching on the residual strength of beams for different cements. Schneider (1992, 1999) has performed experiments on beams subjected to different aggressive solutions and has observed a decrease of maximal strength with time. A loss of elastic properties and a loss of strength have also been observed experimentally by Gérard (1996) and Carde (1996).

Some theoretical models have been developed in order to describe all these coupled chemomechanical effects. One of the main limitations of existing models is, however, that they are not validated against experiments on structural elements. The model developed by Gérard (1996), which is of main concern in this paper, uses a finite-element analysis coupling leaching and a nonlocal damage mode (Pijaudier-Cabot and Bazant 1987); it is able to capture the decrease of the residual strength and the lifetime of concrete structures subjected to leaching (Gérard et al. 1998). An important point of this paper is to contribute the validation of some assumptions used in

${ }^{1}$ Electricité de France, Res. and Devel. Div., Dept. MTC, 77818 Moretsur-Loing, Cedex, France; LMT Cachan, ENS Cachan/CNRS/Université Paris VI, 61 Avenue du Président Wilson, 94235 Cachan. E-mail: Caroline.Le-Bellego@edf.fr

${ }^{2}$ Electricité de France, Res. and Devel. Div., Dept. MTC, 77818 Moretsur-Loing, Cedex, France. E-mail: Bruno.Gerard@edf.fr

${ }^{3}$ LMT Cachan, ENS Cachan/CNRS/Université Paris VI, 61 Avenue du Président Wilson, 94235 Cachan. E-mail: Gilles.Pijaudier-Cabot@ Imt.ens-cachan.fr

Note. Associate Editor: Christopher K. Y. Leung. Discussion open until August 1, 2000. To extend the closing date one month, a written request must be filed with the ASCE Manager of Journals. The manuscript for this paper was submitted for review and possible publication on October 13, 1999. This paper is part of the Journal of Engineering Mechanics, Vol. 126, No. 3, March, 2000. (C)ASCE, ISSN 0733-9399/00/0003-0266$0272 / \$ 8.00+\$ .50$ per page. Paper No. 21008 this model. As described in detail in Gérard (1996) and Gérard et al. (1998), an aging variable $V$, which is a function of the calcium content, is introduced in the equations

$$
E=E_{0}(1-V) ; \quad G_{f}=G_{f 0}(1-V)
$$

where $E_{0}$ and $G_{f 0}=$ Young's modulus and fracture energy of the sound (nondegraded) material, respectively; and $E$ and $G_{f}$ $=$ those of the degraded material.

An internal length $l_{c}$ is introduced in the nonlocal damage model. Physically, $l_{c}$ characterizes the area where microcracks occur in front of a propagating crack tip. It is a material parameter and a function of the size of heterogeneity. It is proportional to the fracture energy $G_{f 0}$ (Mazars and PijaudierCabot 1996). Hence, one assumption of the model is that $l_{c}$ and the aging variable $V$ are two independent quantities that act separately on the variation of the fracture energy due to the chemical degradation.

Experimental data are needed to calibrate the model parameters and eventually validate or invalidate the assumptions in (1). For this, an experimental program has been performed with the following aims:

- To measure the entire response of leached bending beams and to evaluate the contribution of the leached part on the global behavior

- To evaluate the effect of size on mechanical response and to obtain experimentally the variation of the fracture energy due to leaching

After having briefly described the fundamental mechanisms that occur during the leaching process, the writers present the experimental program concerning the residual mechanical properties of a bending beam, after a chemical degradation has been performed. The last part of the paper is devoted to the interpretation of the results in terms of the influence of the degradation and size effect.

\section{PHYSICO-CHEMICAL AND MECHANICAL MECHANISMS OF WATER HYDROLYSIS ON CEMENT-BASED MATERIALS: BRIEF REVIEW}

Concrete or mortars are porous materials. Hydrates [portlandite $\mathrm{Ca}(\mathrm{OH})_{2}$, hydrated calcium silicates C-S-H, etc.] and water are the main components of the binder. Solid phases are in thermodynamic equilibrium with the surrounding pore solution. The hydrates leaching process is caused by the difference in composition and chemical activity of the solution outside with concrete and of the pore solution inside concrete. The different in ionic concentration between the solutions causes the motion of ions essentially outside the material. It 
breaks the thermodynamic equilibrium established between the pore solution and the hydration products and induces the dissolution of solid phases such as portlandite and C-S-H.

Calcium is the main chemical component of the cement paste. For this reason, many authors studied the hydrolysis mechanisms by measuring globally the evolution of the calcium content in the liquid and solid phases. The equilibrium between solid and ionic solute species is characterized by a two-step curve on a plot of the calcium content in the solid phase versus the calcium content in the pore solution (Fig. 1). At high concentrations of calcium ions in the pore solution, $\mathrm{C}-\mathrm{S}-\mathrm{H}$ and $\mathrm{Ca}(\mathrm{OH})_{2}$ cannot be dissolved. The first equilibrium front describes the dissolution of portlandite $\mathrm{Ca}(\mathrm{OH})_{2}$. When all the available portlandite has been leached, the equilibrium of the system is controlled by the $\mathrm{C}-\mathrm{S}-\mathrm{H}$, which themselves undergo partial decalcification. The second front corresponds to the final decalcification stage of hydrates.

In fact, the degradation of cement is made of several dissolution fronts, depending on the relative solubility of each hydrate (Adenot 1992). The rate at which these fronts evolve depends not only on the solubility of the hydrates but mainly on the diffusivity of the ionic species. The dissolution front of portlandite follows a square root function of time when considering a unidirectional diffusion process

$$
x=a \sqrt{t}
$$

where $x=$ penetration depth of portlandite dissolution $(\mathrm{mm})$; $t=$ time (years); and $a=$ constant (Table 1).

The consequences of leaching on the cement paste microstructure are a decrease of the $\mathrm{pH}$ of the pore solution, an increase of porosity [as shown in Fig. 2(a) (Gérard 1996; Le Maréchal et al. 1998], and, as a consequence, a decrease of

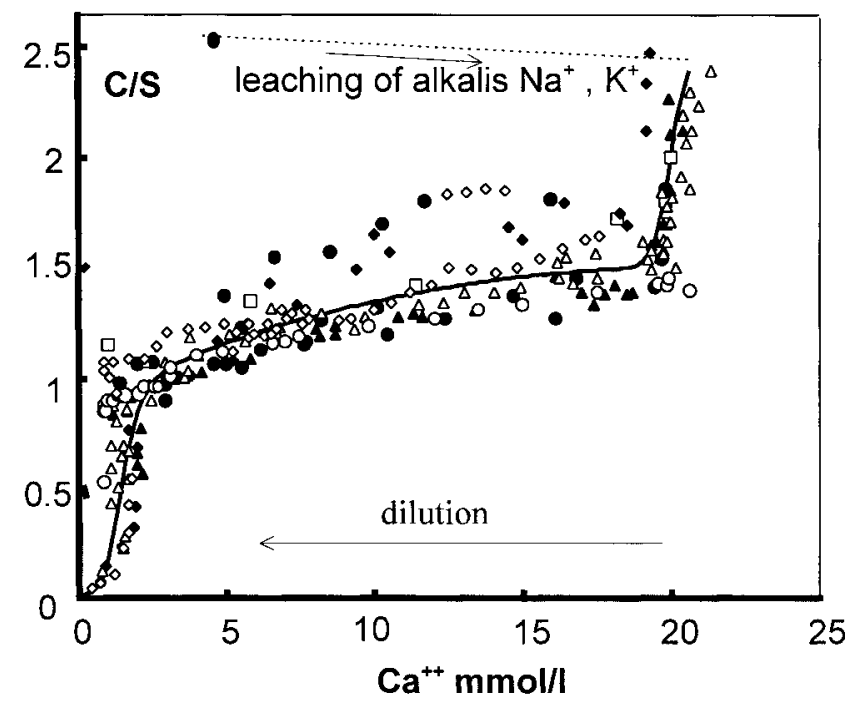

FIG. 1. Equilibrium Diagram Giving Solid Calcium C-Solid Silica S Ratio as Function of Calcium Concentration in Pore Solution $\mathrm{Ca}^{++}$(Berner 1992; Gérard 1996)

TABLE 1. Example of Kinetics of Calcium Leaching for Cement Pastes

\begin{tabular}{l|c|c}
\hline \hline $\begin{array}{c}\text { Reference } \\
(1)\end{array}$ & $\mathrm{W} / \mathrm{C}$ & $\begin{array}{c}a=x / t^{0.5} \\
\left(\mathrm{~mm} \cdot \mathrm{y}^{-0.5}\right) \\
(3)\end{array}$ \\
\hline Adenot (1992) & $(2)$ & 2.3 \\
Delagrave (1996) & 0.4 & 1.6 \\
& 0.25 & 1 \\
& $0.6 \% \mathrm{SF}^{\mathrm{a}}$ & 5.5 \\
& $0.45+6 \% \mathrm{SF}$ & 3.6 \\
\hline
\end{tabular}

${ }^{\mathrm{a}} \mathrm{SF}=$ silica fume.

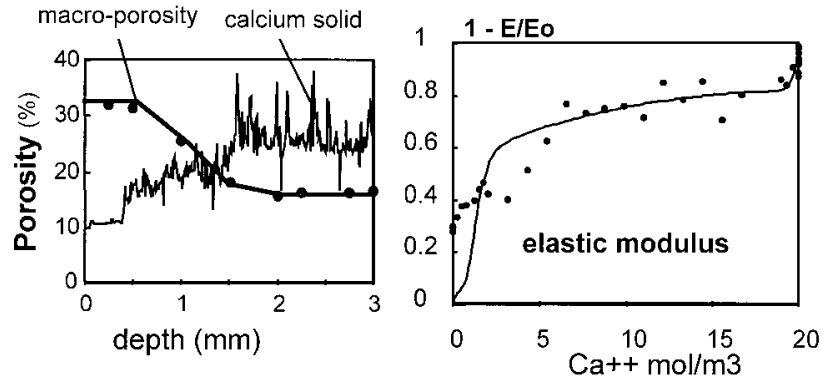

FIG. 2. Consequences of Calcium Leaching on Cement Paste on Porosity and Elasticity, Obtained by Microhardness (Gérard 1996; Le Maréchal et al. 1998)

the Young's modulus of the material. Fig. 2(b) shows the variation of the Young's modulus as a function of the solid calcium content in a cement paste. These data can be obtained from microhardness tests (Gérard 1996). As a consequence, leaching influences the structural behavior of mortar and concrete structures; a loss of stiffness and of maximal strength is expected.

Over the years, two different kinds of models have been developed to describe the calcium leaching: the geochemist or chemo-physical approaches and the simplified chemo-mechanical approaches (Gérard et al. 1999).

The chemo-physical approaches consist in solving the different equations governing the transport of each species in the pore solution. These take into account the intricate thermodynamical equilibria between each species and also model the kinetics of dissolution-precipitation of solid phases. These models are usually solved using two numerical techniques: finite differences or finite elements (Yeh and Tripathi 1989). Adenot (1992) used such an approach to predict the leaching of cement-based materials. These models can predict the appearance of different zones that correspond to the hydrolysis of a specific hydrate. They are useful in investigating the fundamental physical mechanisms involved in the leaching process. However, their use for $2 \mathrm{D}$ and $3 \mathrm{D}$ applications is complex and their coupled effects with mechanical properties are not realistic in terms of computing and practical considerations.

Simplified-e.g., phenomenological—approaches avoid considering all the elementary chemical mechanisms and focus on the evolution of one variable only, which is generally the concentration of calcium ions in the liquid phase. For Brandstetter et al. (1994), the parameter was the maximum leaching depth (dissolution of portlandite). A square root function of time was proposed for its growth. Buil et al. (1990) and Gérard et al. $(1996,1998,1999)$ proposed modeling the hydrolysis by considering the mass conservation of calcium. The leaching prediction is obtained by solving a nonlinear diffusion equation:

$$
f\left(C a^{++}\right) \frac{\partial C a^{++}}{\partial t}=\operatorname{div}\left\{D\left(C a^{++}, d\right) \operatorname{gra} \mathrm{d}\left(C a^{++}\right)\right\}
$$

where $D=$ diffusion coefficient, which depends on the mechanical damage parameter $d$ (Mazars 1984) and on the calcium content in the pore solution. The assumptions are: local equilibrium, water saturation, and isothermal conditions. The internal mechanical damage variable $d$, which goes from 0 (uncracked material) to 1 (cracked material), is introduced in order to capture the influence of microcracking on leaching. The Young's modulus of the material subjected to chemical leaching and mechanical degradation (microcracking) is given by the simple multiplicative rule

$$
E=(1-V)(1-d) E_{0}
$$


where $V=$ aging variable (chemical damage), which depends solely on the calcium content; and $E_{0}=$ Young's modulus of the sound material. The damage variable $d$ is controlled by an average scalar measure of the strain $\tilde{\varepsilon}$, denoted $\bar{\varepsilon}$ :

$$
d=f(\bar{\varepsilon})
$$

$\bar{\varepsilon}=\frac{1}{V_{r}(x)} \int_{\Omega} \Psi(x-s) \tilde{\varepsilon}(s) d s \quad$ with $\quad V_{r}(x)=\int_{\Omega} \Psi(x-s) d s$

$\Omega=$ volume of the structure; $V_{r}(x)=$ representative volume centered at $x$; and $\Psi(x-s)=$ nonlocal weight function, with

$$
\Psi(x-s)=\exp \left(-\frac{4\|x-s\|^{2}}{l_{c}^{2}}\right)
$$

where $l_{c}=$ internal mechanical length of the material. For more details on specific definitions, see Pijaudier-Cabot and Bazant (1987) and Mazars and Pijaudier-Cabot (1996). Because the material is described by a nonlocal damage model, as far as the mechanical aspects are concerned, the internal length $l_{c}$ is proportional to the fracture energy $G_{f 0}$ of the sound material (Mazars and Pijaudier-Cabot 1996). Hence, it follows from (4) that the fracture energy is a linear function of the aging variable $V$, as shown in (1), and a linear function of the internal length. These two influences are entirely independent.

Several numerical simulations have been published that show the influence of the fracture energy, the tensile strength, and the diffusivity on lifetime predictions of beams subjected to fixed displacement and leaching (Gérard et al., 1998, 1999; Molez et al. 1998). It has been shown that the influence of the internal length $l_{c}$ on the fracture energy $G_{f}$ is important.

This is the reason why an experimental program on a mortar bending beams has been performed that could serve for calibrating other types of models as well. Compressive and tensile tests have been also performed on cylindrical samples made with the same mortar (Kamali 1999). In order to be able to transpose the laboratory results to real structures, different sizes of samples have been studied, and size effect was analyzed. The originality of these experiments is that the entire response of simple structures subjected to mechanical loads and chemical attack is obtained and size effects experiments are available so that one may calibrate (by inverse methods) modern constitutive relations for failures that incorporate an internal length.

\section{EXPERIMENTAL INVESTIGATIONS AND RESULTS}

The experimental program performed consists of residual strength tests; the residual behavior of mortar beams is obtained after leaching in an aggressive solution.

The specimens are mortar beams of a rectangular cross section [Fig. 3(a)]. Different sizes of beams have been cast: geometrically similar specimens of heights $D=80,160$, and 320 $\mathrm{mm}$ and length $L=4 D$. The thickness $B=40 \mathrm{~mm}$ was kept constant for all the specimens. It appears from experience that there is no significant difference in the size effect analysis between the case where $B$ is kept constant and the case where $B$ is proportional to $D$ (Bazant and Planas 1998). The lengthto-height ratio is $L / D=4$ and the span-to-height ratio is $l / D=$ 3 for all specimens. Specimens were cast in the vertical position, using a water-cement ratio of 0.4 and a cement-sand ratio of 0.46 (all by weight). The maximal sand grain size is $d_{a}=3 \mathrm{~mm}$ (Table 2). Curing conditions were 4 months at $100 \%$ RH (humidity room) at $23^{\circ} \mathrm{C}$.

The leaching kinetics is a very slow process (a few centimeters per hundred years). In order to collect experimental data in a reasonable period of time, it is necessary to use an accelerated procedure. Different techniques exist (Le Maréchal et al. 1998; Gérard et al. 1999), including acid solution, simple (a)

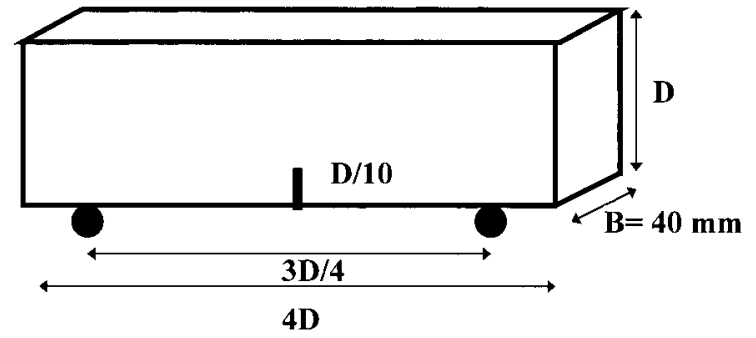

(b)

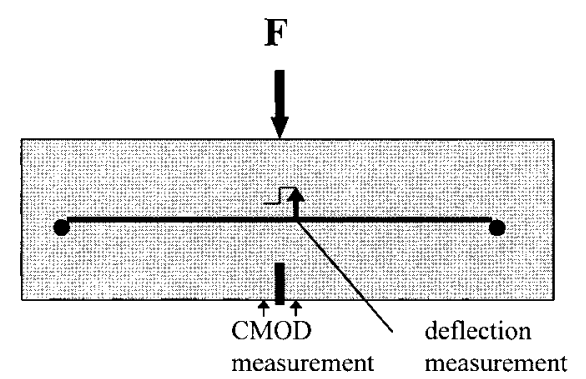

FIG. 3. (a) Description of Mortar Samples; (b) Description of Instrumentation for Mechanical Test

TABLE 2. Mortar Mixture

\begin{tabular}{c|c|c|c|c|c}
\hline \hline & $\begin{array}{c}\text { Sand Sika } \\
\text { S36 }\end{array}$ & $\begin{array}{c}\text { Sand Sika } \\
\text { S32 }\end{array}$ & & & \\
Cement CPA & $(0.8-3.15$ & $(0.16-0.2$ & Water; & & \\
$\begin{array}{c}\text { CEM I 42.5 } \\
(1)\end{array}$ & $\mathrm{mm})$ & $\mathrm{mm})$ & W/C & Rc28 & Slump \\
$(2)$ & $(3)$ & $(4)$ & $(5)$ & $(6)$ \\
\hline $639 \mathrm{~kg} / \mathrm{m}^{3}$ & $414 \mathrm{~kg} / \mathrm{m}^{3}$ & $966 \mathrm{~kg} / \mathrm{m}^{3}$ & $256 \mathrm{~kg} / \mathrm{m}^{3} ; 0.4$ & $45 \mathrm{MPa}$ & $11 \mathrm{~cm}$ \\
\hline \hline
\end{tabular}

leaching with pure water (Adenot 1992), leaching in an electric field (Gérard 1996), and ammonium nitrate (Schneider et al. 1992; Carde 1996; Tognazzi 1998). For this study, an ammonium nitrate solution $\mathrm{NH}_{4} \mathrm{NO}_{3}$ has been selected at a concentration of $480 \mathrm{~g} / \mathrm{l}$ (of solution) and kept at $30^{\circ} \mathrm{C}$. Carbonation is avoided by nitrogen bubbling. $\mathrm{NH}_{4} \mathrm{NO}_{3}$ has been chosen because of the accessibility of various published data using the same aggressive solution and the same material mixture (Mohr 1925; Lea 1965; Schneider 1992; Carde et al. 1996; Tognazzi 1998).

Ammonium nitrate reacts essentially with calcium according to the following reactions:

$$
\begin{gathered}
\mathrm{NH}_{4} \mathrm{NO}_{3} \Leftrightarrow \mathrm{NH}_{4}^{+}+\mathrm{NO}_{3}^{-} \\
\mathrm{Ca}(\mathrm{OH})_{2} \Leftrightarrow \mathrm{Ca}^{2+}+2 \mathrm{OH}^{-} \\
\mathrm{NH}_{4}^{+}+\mathrm{OH}^{-} \Leftrightarrow \mathrm{NH}_{4} \mathrm{OH} \Leftrightarrow \mathrm{NH}_{3}+\mathrm{H}_{2} \mathrm{O} \\
\mathrm{Ca}^{2+}+2 \mathrm{NO}_{3}^{-} \Rightarrow \mathrm{Ca}\left(\mathrm{NO}_{3}\right)_{2}
\end{gathered}
$$

Thus, the general reaction equation is

$$
2 \mathrm{NH}_{4} \mathrm{NO}_{3}+\mathrm{Ca}(\mathrm{OH})_{2} \Rightarrow \mathrm{Ca}\left(\mathrm{NO}_{3}\right)_{2}+2 \mathrm{NH}_{3}+2 \mathrm{H}_{2} \mathrm{O}
$$

The dissolution of portlandite $\mathrm{Ca}(\mathrm{OH})_{2}$ is higher than that in pure water: 100 times higher for a OPC (ordinary portland cement) paste with a 0.5 water-cement ratio (Carde et al. 1996). The beams are immersed into the aggressive solution during different periods of time (28.56, and 98 days). Only the two lateral sides of the beams are exposed to leaching in order to have two unidirectional leaching fronts through the thickness of the beam. Hence, the leaching process is the same for all the beam sizes. The other faces are coated with a silicon resin, so that ammonium nitrate can not penetrate [Fig. 4(a)]. The maximal leaching front moves from the external surface to the center of the beam. In a cross section of a leached beam, three zones are observed: a sound zone in the center surrounded by two leached zones (depth $x_{d}$ ) [Fig. 4(b)]. 
(a)

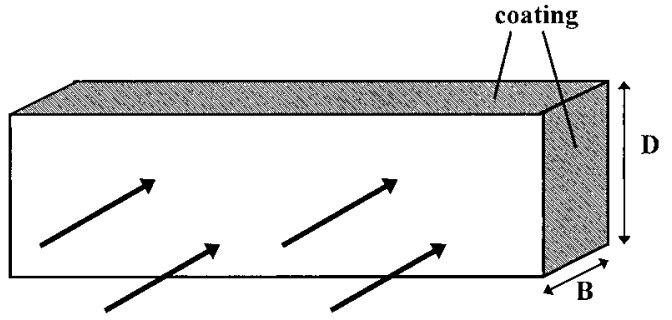

Ammonium nitrate $\mathrm{NH}_{4} \mathrm{NO}_{3}$

(b)

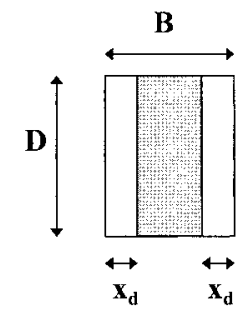

Leaching rate $\mathbf{L}_{\mathbf{R}}=\frac{2 x_{d}}{B}$

FIG. 4. (a) Coating of Samples Where Only Lateral Faces Are Exposed; (b) Cross Section of Leached Beam and Definition of Leaching Rate $L_{R}$

TABLE 3. Leached Depths for Different Periods of Immersion

\begin{tabular}{c|c|c}
\hline \hline $\begin{array}{c}\text { Time of immersion } \\
\text { (days) } \\
(1)\end{array}$ & $\begin{array}{c}\text { Phenolphtalein } \\
\text { measures } x_{d} \\
(\mathrm{~mm})\end{array}$ & $\begin{array}{c}\text { Microprobe } \\
\text { measures } x^{*} \\
(\mathrm{~mm})\end{array}$ \\
\hline 28 & $(2)$ & $(3)$ \\
56 & 7.5 & 9 \\
98 & 11 & 12.7 \\
\hline
\end{tabular}

The leaching depth $x_{d}$ is measured by penetration of phenolphtalein (Schneider et al. 1998) after failure. Phenolphtalein reacts with the $\mathrm{pH}$ of the pore solution, which is a good indicator of leaching. This technique has been employed; the leached depths $x_{d}$ after different periods of immersion in the aggressive solution are given in Table 3 . The kinetics follows a square root function of time that was also experimentally verified by Carde (1996) and Tognazzi (1998):

$$
x_{d}=1,46 \sqrt{t}
$$

Phenolphtalein changes its color when the $\mathrm{pH}$ is about 9. During the degradation of the concrete, the $\mathrm{pH}$ goes from 13 to the $\mathrm{pH}$ of the external solution $(\mathrm{pH}=5)$. Therefore, it does not measure the maximal degraded depth $x^{*}$, and a complementary microstructural analysis using an electronic microprobe has been realized to correct the measure given by using phenolphtalein. Using microprobe analysis, a mortar sample after a 28-day leaching has a $9 \mathrm{~mm}$ maximal degraded depth. The result shows different fronts in the material: a first zone where the calcium content is low, a transitional zone where it increases, and then a sound zone where it is the same as the reference sample. This complementary analysis and the fact that the kinetic follows a quite perfect diffusion-governed process yields a correction of (7) by an affinity of 1,16 (on an $x *$ versus $\sqrt{t}$ plot):

$$
x^{*}=1,7 \sqrt{t}
$$

After the chemical degradation is performed, the specimens are loaded using a three-point bending procedure. All the tests are carried out on the same $100 \mathrm{kN}$ MTS machine. A notch of depth $D / 10$ and thickness $3 \mathrm{~mm}$ (the same for all specimens) is sawed at the center of each specimen, on the bottom face, just before the mechanical test [Fig. 3(a)]. The tests are notch opening controlled. A second extensometer follows the deflection of a central point of the beam [Fig. 3(b)]. This deflection is measured between a steel beam fixed on two supports at half height and at the ends of the beams, and a metallic plate is glued on the specimen at mid span and half height. Two types of curves are recorded: load versus CMOD (crack mouth opening displacement) curves and load versus deflection curves. A good repeatability has been verified, as shown in Fig. 5 for small size specimens leached for 56 days. Some unloading-reloading cycles were performed in order to obtain the evolution of the stiffness of the beam.

In order to calculate an average experimental response for each series of tests, a list of 100 fixed deflection values was defined. Then, the load response of each curve was obtained by linear interpolations (about 3,000 points are recorded for each test, so that the interpolation is accurate enough). Average curves are obtained from a minimum of 3 curves (except for
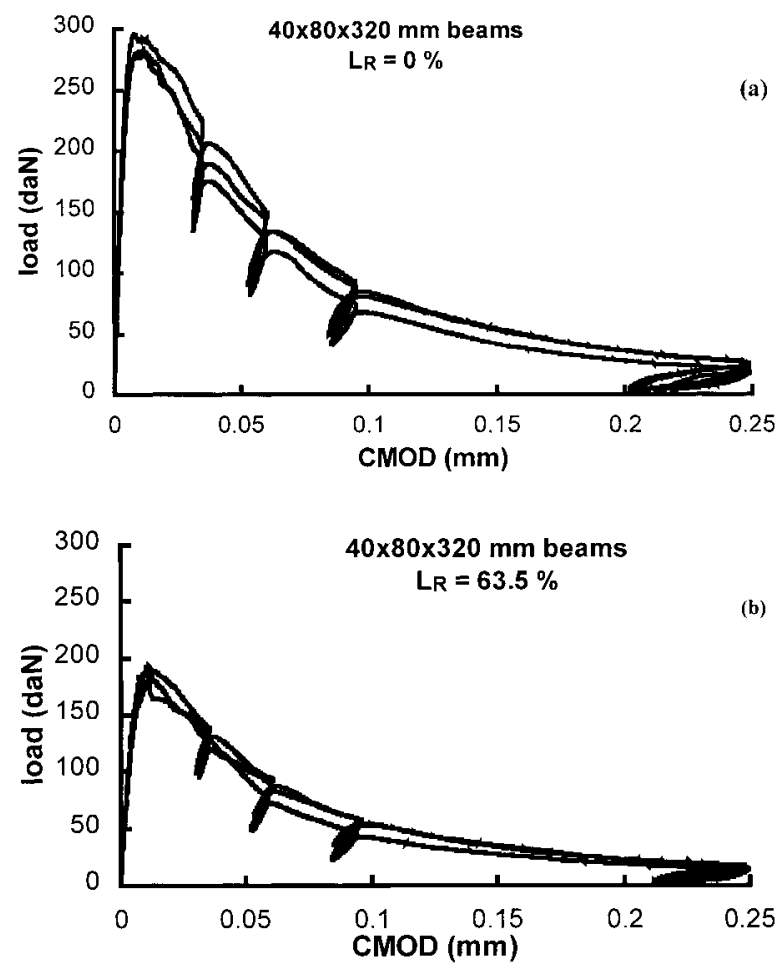

FIG. 5. (a) Load-CMOD Curves on Sound Samples $40 \times 80 \times$ $320 \mathrm{~mm}^{3}$; (b) Load-CMOD Curves on 56-Day Leached Samples $40 \times 80 \times 320 \mathrm{~mm}^{3}\left(L_{R}=63.5 \%\right)$

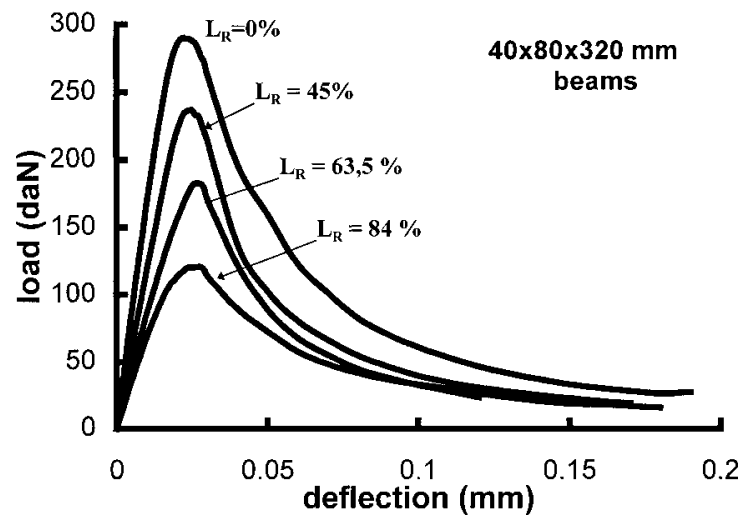

FIG. 6. Influence of Leaching Rate $L_{R}$ on Structural Behavior, Average Load-Deflection Curves for Different Leaching Rates on $40 \times 80 \times 320 \mathrm{~mm}^{3}$ Beams 
the large size specimen after a 28-day leaching period where only one test is available). Fig. 6 shows the average responses for all the leaching rates (load as a function of CMOD and deflection) and for the small size beams $(40 \times 80 \times 320$ $\left.\mathrm{mm}^{3}\right)$. It is noteworthy that the deflection at peak is almost independent from leaching. The leaching rate, defined as $L_{R}=$ $2 x_{d} / B$, is the percentage of the cross section of the beam that has been leached. It influences the mechanical behavior of beams; the higher the leaching rate, the lower the stiffness and the maximal length. Fig. 7 shows the average results on a loaddeflection plot for the three sizes of beam and three leaching rates.

\section{INTERPRETATION OF RESULTS}

On the basis of the microprobe observations, the writers simplified modeling, assuming that the degraded zone is homogenized. Thus, degraded beams are made of two parts: a sound zone, which is $\left(B-2 x^{*}\right) \mathrm{mm}$ thick, and a degraded zone, which is $\left(2 x^{*}\right) \mathrm{mm}$ thick [Fig. 4(b)]. The global mechanical response of a degraded beam is the sum of the behavior of two beams in parallel: a leached beam and a sound
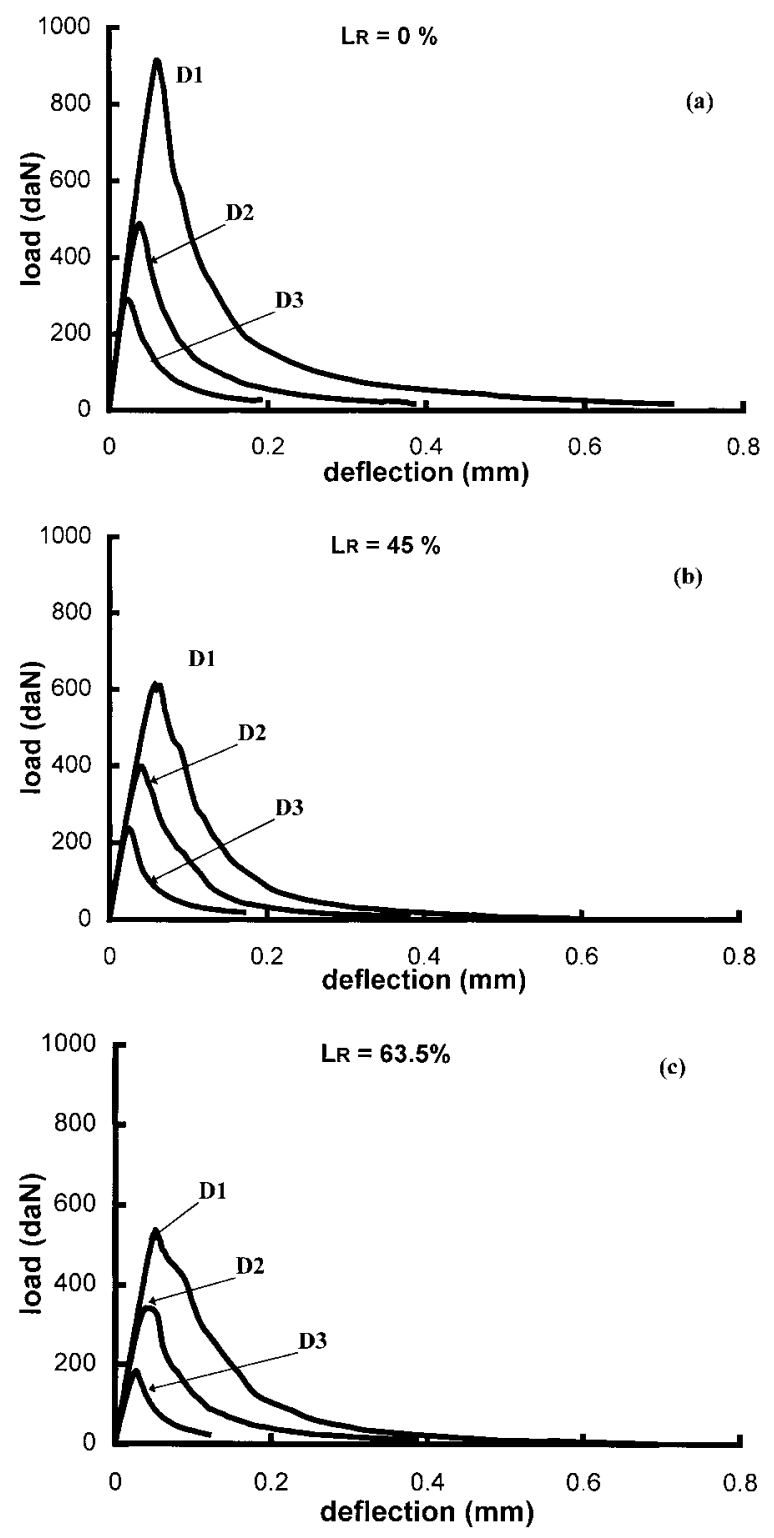

FIG. 7. Curves Representing for Each Size (D1 = 320 mm; D2 $=160 \mathrm{~mm}$; D3 = $80 \mathrm{~mm}$ ) Average Load-Deflection Curves for (a) Sound Samples $L_{R}=0 \%$; (b) 28-Day Leached Samples $L_{R}=$ 45\%; (c) 56-Day Leached Samples $L_{R}=63.5 \%$ beam. For a given deflection $\delta$, if $F_{s}(\delta)$ is the mechanical response of a $1 \mathrm{~mm}$ thick sound beam and $F_{d}(\delta)$ is the mechanical response of a $1 \mathrm{~mm}$ thick chemically degraded beam, the mechanical response $F(\delta)$ of the global beam is

$$
F(\delta)=F_{s}(\delta) *\left(B-2 x^{*}\right)+F_{d}(\delta) *\left(2 x^{*}\right)
$$

where $B=40 \mathrm{~mm}$ is the total thickness of the beam; and $x *$ $=$ maximal leached depth $(\mathrm{mm})$.

By subtracting the contribution of the sound beam behavior $F_{s}(\delta) *\left(B-2 x^{*}\right)$ to the average global leached beams behavior $F(\delta)$, we obtain the response of the average degraded beam behavior $F_{d}(\delta) *(2 x)$.

Fig. 8 shows the calculated responses of $1 \mathrm{~mm}$ thick beams for the three sizes, which are sound and degraded. Here, $F_{d}(\delta)$ has been determined from the global response $F(\delta)$ after a 28 -day leaching period. Average curves are used when available.

Knowing the response of the degraded beams and the leach-

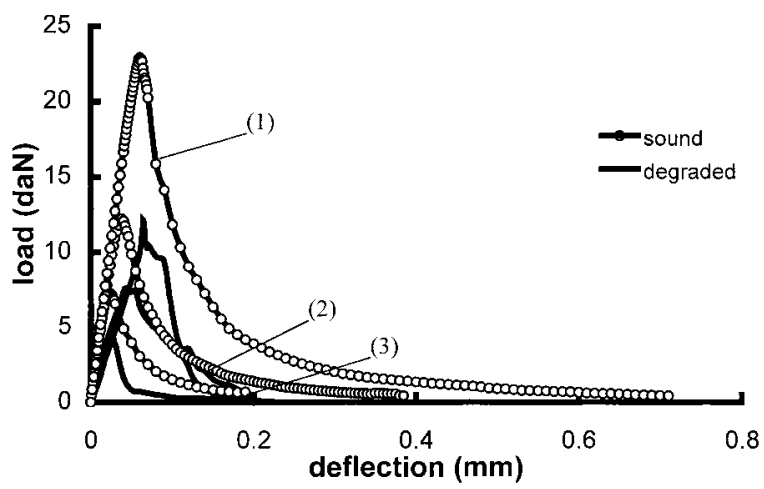

FIG. 8. Mechanical Behavior of Sound Beams (1 $\mathrm{mm}$ Thick) and Homogeneous Degraded Beams (1 mm Thick) for Sizes (1) $=320 \mathrm{~mm} ;(2)=160 \mathrm{~mm} ;(3)=80 \mathrm{~mm}$
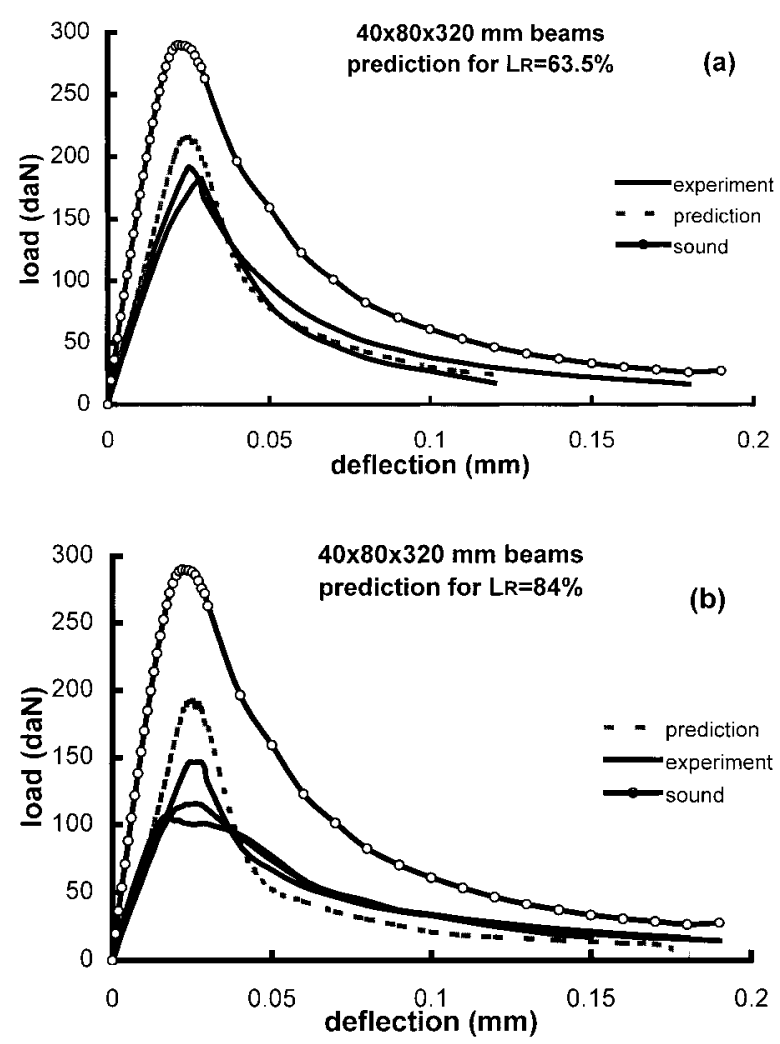

FIG. 9. Prediction of $40 \times 80 \times 320 \mathrm{~mm}^{3}$ Beams Behavior: (a) for $L_{R}=63.5 \%$ (after 56-Day Leaching); (b) for $L_{R}=84 \%$ (after 98-Day Leaching) 
ing rates, the behavior of beams after 56-day and 98-day leaching periods can be predicted according to (12). Predictions are compared with the experimental results in Figs. 9 and 10. For the purpose of comparisons, the response of sound beams is also plotted. The results are quite satisfying, demonstrating that the above interpretation, which provides the response $F_{d}(\delta)$ of completely degraded beams, is a good approximation.

Bazant (1998) proposed a procedure to characterize the size effect on bending beams of geometrically similar sizes. The maximal strength is calculated according to the classical formula for a beam of unit thickness

$$
\sigma=\frac{3}{2} \frac{F L}{D^{2}}
$$

where $D=$ height $(\mathrm{mm}) ; L=$ length $(\mathrm{mm})$; and $F=$ maximal load $(\mathrm{N})$. The peak forces $F$ are obtained from Fig. 8, for each size, for the sound $F_{s}(\delta)$ and the leached $F_{d}(\delta)$ contributions. The maximal strengths are given in Table 4 . The simple size effect law for concrete and others materials proposed by $\mathrm{Ba}-$ zant and Planas (1998) is used in this paper:

$$
\sigma=\frac{\beta f_{t}^{\prime}}{\sqrt{1+D / D_{0}}}
$$

where $f_{t}^{\prime}=$ tensile strength of the material; $D_{0}=$ a character-
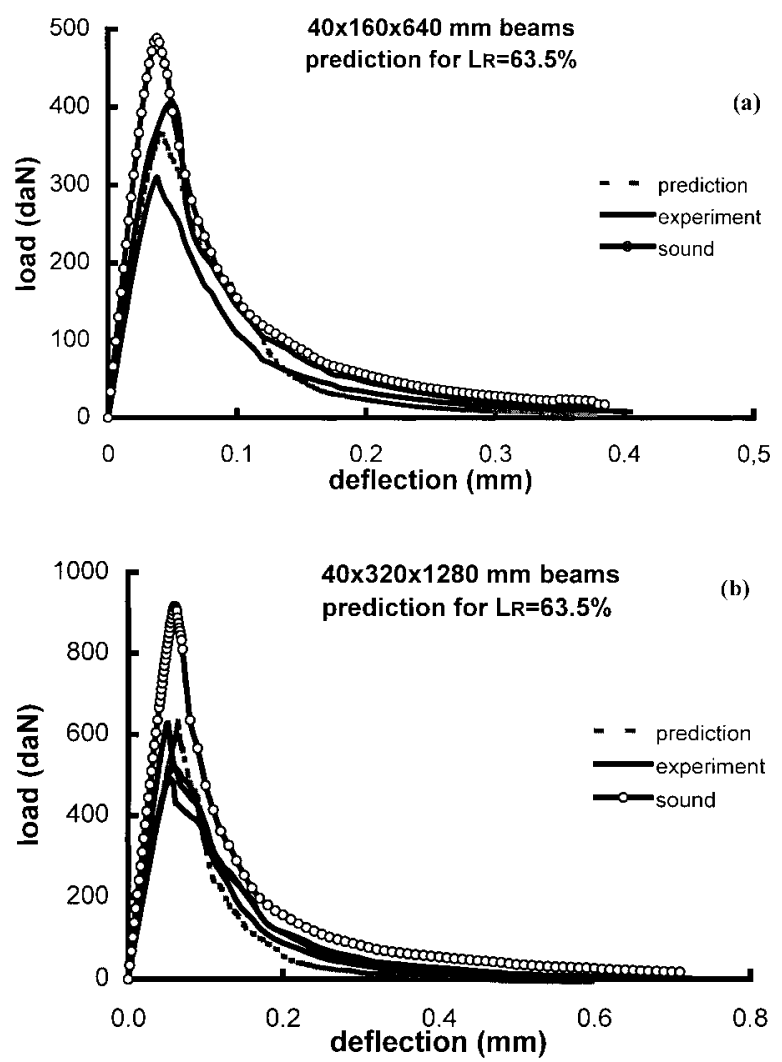

FIG. 10. Prediction of Samples Behavior for (a) $40 \times 160 \times 640$ $\mathrm{mm}^{3}$ Samples, $L_{R}=63.5 \%$ after 56-Day Leaching; (b) $40 \times 320 \times$ $1,280 \mathrm{~mm}^{3}$ Samples, $L_{R}=63.5 \%$ after 56-Day Leaching

TABLE 4. Size Effect Analysis for Sound Beam and Leached Beam

\begin{tabular}{l|c|c|c|c|c}
\hline \hline & \multicolumn{3}{|c|}{$\sigma(\mathrm{MPa})$} & & \\
\cline { 2 - 4 } & $\mathrm{D} 1=80$ & $\mathrm{D} 2=160$ & $\mathrm{D} 3=320$ & & \\
Beam type & $\mathrm{mm}$ & $\mathrm{mm}$ & $\mathrm{mm}$ & $E\left(\mathrm{~N} / \mathrm{mm}^{2}\right)$ & $G_{f}(\mathrm{~N} / \mathrm{m})$ \\
$(1)$ & $(2)$ & $(3)$ & $(4)$ & $(5)$ & $(6)$ \\
\hline Sound & 4.08 & 3.43 & 3.22 & 45,000 & 47.17 \\
Degraded & 2.45 & 2.14 & 1.71 & 16.000 & 24.12 \\
\hline \hline
\end{tabular}

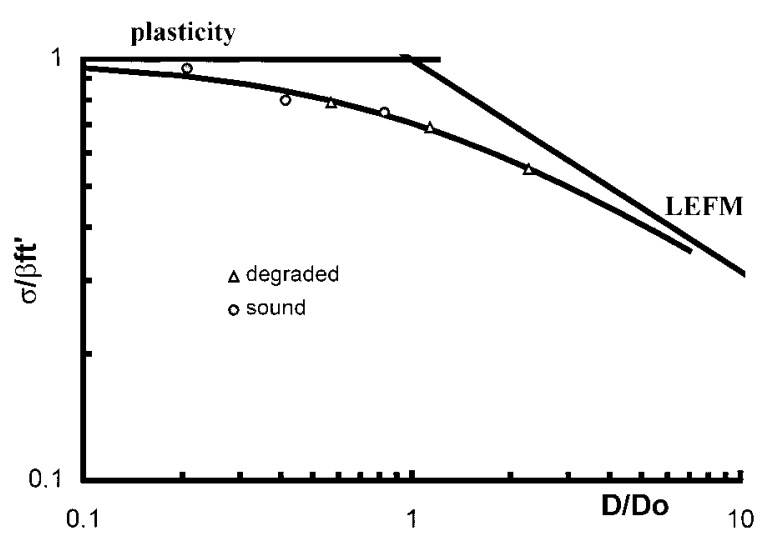

FIG. 11. Bazant's Size Effect Law: Calibration for Degraded and Sound Beams

istic size that corresponds to a change of mechanisms between plasticity phenomena and fracture mechanics; and $\beta=$ a material parameter. Results have been represented in a $\left(\sigma / \beta f_{t}^{\prime}-\right.$ $D / D_{0}$ ) diagram (Fig. 11). Pure plasticity and LEFM (linear elastic fracture mechanics) theoretical responses are also shown. The larger the beam, the lower the relative strength. A variation of about $20 \%$ is measured comparing the two extreme sizes. Moreover, it can be noticed that the mechanical failure of the leached beam tends to adhere more to fracture mechanics than to plasticity, since the data for chemically degraded specimen shift right on the size effect plot.

In order to calculate the fracture energy $G_{f}$, a linear regression type I (Bazant and Planas 1998) has been used ( $a$ and $c$ are constant):

$$
\frac{1}{\sigma^{2}}=a D+c
$$

Hence, $G_{f}$ is computed as

$$
G_{f}=\frac{k_{0}^{2}}{E} \frac{1}{a}
$$

where $k_{0}$ is a parameter that depends on the geometry of the beams (here, $k_{0}$ is equal to 0.546 ). The elastic moduli $E_{0}$ of the sound mortar and $E$ of the degraded mortar (average degradation) have been determined from compressive tests on the same material, with the same leaching procedure (Kamali 1999) (Table 4):

$$
E=0.37 E_{0}
$$

According to (4), the average aging variable $V$ is 0.63 . From (12), the fracture energy of the degraded and sound materials can be evaluated. According to the linear regression on the tests results for sound beams, the writers found $G_{f 0}=47.2$ $\mathrm{N} / \mathrm{m}$ and

$$
G_{f}=(1-0.49) G_{f 0} \neq(1-V) G_{f 0}
$$

This demonstrates the fact that (1) could not be transposed to calculate the dissipated energy in a structural problem. The effect of leaching on the fracture energy would be more complex than expected. However, this result is derived from a simplified analysis and with a limited number of tests on large size specimens [which can have a sensitive influence on the regression in (15)]. Other physical facts should be investigated in more detail; the dependence of fracture energy on Young's modulus may also be linked to the effect of leaching on solid surface energy. Application of LEFM may introduce error. Nonlinear fracture mechanics may be more appropriate for further refinements to the model. The use of (13) for maximum strength may be subject to significant error due to the fact that a span-to-depth ratio of 3 is used for the experiment. 


\section{CONCLUSION}

Among aggressions on concrete structures, leaching due to aggressive water can be responsible for a loss of mechanical properties and stability of concrete structures. In order to quantify this loss of mechanical properties due to leaching, accelerated tests have been performed; an ammonium nitrate $\mathrm{NH}_{4} \mathrm{NO}_{3}$ solution $\left(480 \mathrm{~g} / \mathrm{l}, 30^{\circ} \mathrm{C}\right.$, agitation $)$ has been selected as a representative aggressive solution. Beams of three different sizes have been immersed for different periods of time in the aggressive solution, and their residual mechanical behavior has been measured using a three-point bend procedure. This provides an available and accurate database for further researches.

The principal results are a loss of apparent stiffness, a decrease of maximal load, and a decrease of fracture energy when leaching increases. Considering that the leached part is constituted of an homogeneous material, the data can be interpreted considering two beams in parallel: a degraded beam of which depth has been evaluated from the kinetics of the degradation and a sound beam. Once mechanical characteristics of the degraded beam are determined for a given leaching rate, predictions can be compared with the experimental results for the other leaching rates. The predictions agree quite well with the experiments. The size effect analysis has been carried out for the sound beams and for the leached beams. This analysis reveals also that the material mechanical behavior is modified by leaching. It is more brittle with a decrease in fracture energy. The correlation between the decrease in fracture energy and the decrease in Young's modulus remains to be established more accurately. More research must be performed to completely analyze these experimental results and improve existing or future models.

\section{ACKNOWLEDGMENTS}

The writers wish to acknowledge Mr. Cossange, Mr. Ménard, Miss Kamali, and Dr. Heinfling (EDF/DRD/MTC) for their valuable contribution to this study.

\section{APPENDIX. REFERENCES}

Adenot, F. (1992). “Durabilité du béton: caractérisation et modélisation des processus physiques et chimiques de dégradation du ciment,' $\mathrm{PhD}$ thesis, Université d'Orléans, Orléans, France (in French).

Bazant, Z., and Planas, J. (1998). Fracture and size effect in concrete and other quasibrittle materials. CRC Press, Boca Raton, Fla.

Berner, U. R. (1992). "Evolution of pore water chemistry during degradation of cement in a radioactive waste repository environment." Waste Mgmt., 12, 201-219.

Brandstetter, E. R., Lolcama, J. L., and Reed, S. R. (1994). "An integrated degradation and structural model for predicting the service life of buried reinforced concrete structures for low and intermediate level radioactive waste disposal." Proc., Symp. on Waste Mgmt., Tucson, Arizona, 1, 89-97.

Buil, M., Revertegat E., and Olivier, J. P. (1990). "Modelling cement leaching by pure water.' Proc., 2nd Int. Symp. on Stabilization/Solidification of Hazardous Radioactive and Mixed Wastes, ASTM, West Conshohocken, Pa.

Carde, C. (1996). "Characterization and modeling of the alteration of material properties due to leaching of cement-based materials," $\mathrm{PhD}$ thesis, Université Paul Sabatier, Toulouse, France (in French).
Carde, C., François, R., and Torrenti, J. M. (1996). "Leaching of both calcium hydroxide and $\mathrm{C}-\mathrm{S}-\mathrm{H}$ from cement paste: modelling the mechanical behavior.' Cement and Concrete Res., 26, 1257-1268.

Delagrave, A. (1996). "Mechanisms of chloride ion penetration of normal and high performance cement-based systems,' $\mathrm{PhD}$ thesis, Université Laval, Québec, Canada (in French).

Delagrave, A., Gérard, B., Marchand, J., and Pigeon, M. (1995). "Modelling of the calcium leaching mechanisms in hydrated cement pastes." Mechanisms of chemical degradation of cement-based systems, K. L. Scrivener and S. F. Young, eds., E\&F Spon, London.

Gérard, B. (1996). "Contribution of the mechanical, chemical, and transport couplings in the long-term behavior of radioactive waste respository structures,' PhD thesis, Université Laval, Québec, Canada/ École Normale Supérieure de Cachan, France (in French).

Gérard, B., Didry, O., Marchand, J., Breysse, D., and Hornain, H. (1996). "Modeling the long term durability of concrete barriers for radioactive waste disposals." Mechanisms of chemical degradation of cementbased systems, K. L. Scrivener and F. J. Young, E\&FN Spon, London.

Gerard, B., Pijaudier-Cabot, G., and Laborderie, C. (1998). "Coupled diffusion damage modelling and the implications on failure due to strain localisation.', Int. J. Solids and Struct., 35(31-32), 4107-4120.

Gerard, B., Pijaudier-Cabot, G., and Le Bellego, C. (1999). "Mechanical stability analysis of cement-based materials submitted to calcium leaching: a review."' Proc., 15th Int. Conf. on SMIRT, Seoul, 6, 79-90.

Goncalves, A., and Rodrigues, X. (1991). "The resistance of cement to ammonium nitrate attack."' Durability of concrete: 2nd Int. Conf., CANMET/ACI, Montreal, Canada.

Kamali, S. (1999). "Identification de la loi de comportement mécanique d'un mortier altéré par le nitrate d'ammonium,'” MS thesis, ENS Cachan, France (in French).

Lea, F. M. (1965). "The action of ammonium nitrate salts on concrete." Magazine of Concrete Res., 17(52).

Le Bellego, C. (1999). "Chemo-mechanics of leached concrete structures, structural analysis, and size effects,' $\mathrm{PhD}$ thesis, ENS Cachan, France (in French).

Le Maréchal, J., Gérard, B., Marchand, J., Gagnon, Ph., and Didry, O. (1998). "A new accelerated leaching experiment, the LIFT procedure." Proc., CANMET/ACT 98 on Advanced Concrete Technol., American Concrete Institute, Detroit, Mich.

Mazars, J. (1984). “Application de la mécanique de l'endommagement au comportement non linéaire et à la rupture du béton de structure,', $\mathrm{PhD}$ thesis, LMT ENS Cachan, Paris (in French).

Mazars, J., and Pijaudier-Cabot, G. (1996). "From damage to fracture mechanics and conversely: a combined approach.' Int. J. Solids and Struct., 33, 3327-3342.

Mohr, A. (1925). "Uber die Einwirkung von Ammoniumsalzlösungen auf Beton.' Der Bauingenieur, 6(8), 284-293 (in German).

Pijaudier-Cabot, G., and Bazant, Z. P. (1987). "Nonlocal damage theory.," J. Engrg. Mech., ASCE, 113(10), 1512-1533.

Schneider, U., Nägele, E., Dumat, F., and Holst, S. (1992). "Der Einfluss Mechanisher Spannungen auf den Korrosionwiderstand Zementgebundener Baustoffe.' DAfStB Heft 429, Beuth Verlag GmbH, Berlin (in German).

Schneider, U., Chen, S. W., and Scherpke, G. (1998). "Determination of depth of ammonium nitrate ions in HPC means of phenolphtalein." Proc., 5th Int. Workshop on Mat. Properties and Des., Durable Reinforced Concrete Struct., Aedificatio Publishers, Weimar, Germany.

Schneider, U., and Chen, S. W. (1999). "Behavior of high-performance concrete under ammonium nitrate solution and sustained load." ACI Mat. J., 96(1), 47-51.

Tognazzi, C. (1998). "Cracking and leaching of cement-based materials, experimentation,'” PhD thesis, INSA, Toulouse, France (in French).

Yeh, G. T., and Tripathi, V. S. (1989). "A critical evaluation of recent developments in hydrogeochemical transport models of reactive multichemical components.', Water Resour. Res., 25(1), 93-108. 